\title{
A full color tunable aggregation-induced emission luminogen for bio-imaging based on an indolizine molecular framework
}

Sang-Kee Choi ${ }^{1}$, Jungi Rho', Sang Eun Yoon ${ }^{1}$, Jin-Hong Seok ${ }^{1}$, Hyungi Kim ${ }^{1}$, Junsik Min ${ }^{1}$, Woojin Yoon ${ }^{2}$, Sanghee Lee ${ }^{3}$, Hoseop Yun², O-Pil Kwon ${ }^{1}$, Jong H. Kim¹, Wook Kim ${ }^{1}$, Eunha Kim ${ }^{1 *}$

${ }^{1}$ Department of Molecular Science and Technology, Ajou University, Suwon 16499, Korea ${ }^{2}$ Department of Chemistry, Ajou University, Suwon 16499, Korea

${ }^{3}$ Center for Neuro-Medicine, Brain Science Institute, Korea Institute of Science and Technology, Seoul 02792, Korea

E-mail: ehkim01@ajou.ac.kr

\begin{tabular}{|c|l|c|}
\hline \multicolumn{1}{|c|}{ Table of Contents } & Page NO \\
\hline $\mathbf{1}$ & Supporting figures, tables and scheme & S1 - S11 \\
\hline $\mathbf{2}$ & Copies of ${ }^{1} \mathrm{H}$ and ${ }^{13} \mathrm{C}$ NMR Spectra of a New Compounds & S12- S25 \\
\hline $\mathbf{3}$ & Reference & S26 \\
\hline
\end{tabular}




\section{Supporting figures, tables and scheme}
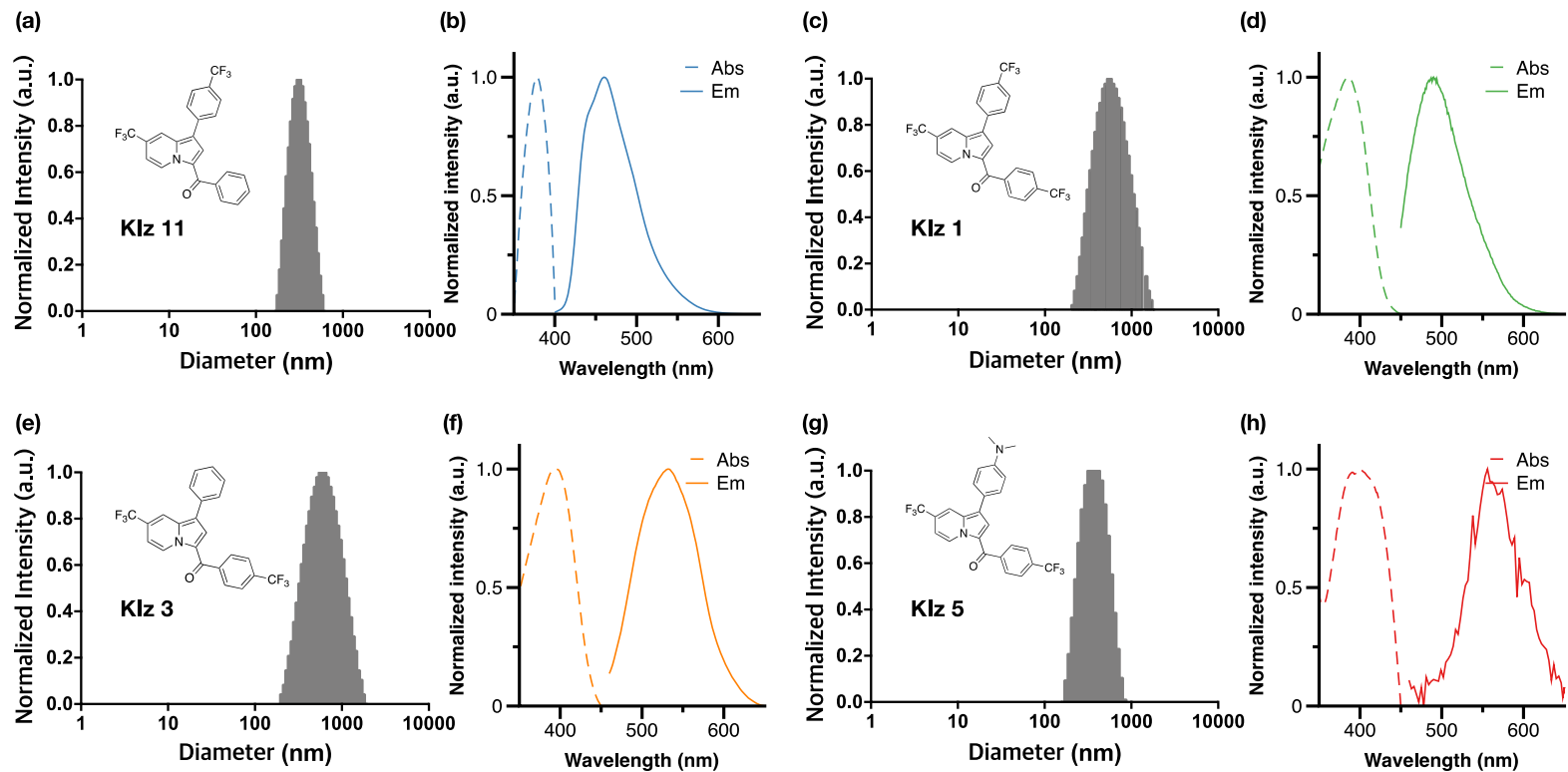

Figure S1. Dynamic light scattering (DLS) analysis of self-aggregates (a,c,e,g) and fluorescence emission spectra (b,d,f,h) of KIz 11 (a,b), KIz 1 (c,d), KIz 3 (e,f) and KIz 5 (g,h) solution in THF/water mixture with $\left(f_{\mathrm{w}}=90 \%\right)$. Note that all of the KIz solution do not give any DLS signals in THF $\left(f_{\mathrm{w}}=\right.$ $0 \%)$. 
Table S1. Photophysical properties and particle sizes of KIz 11, KIz1, KIz3, and KIz 5 in THF/Water Mixtures

\begin{tabular}{|c|c|c|c|c|c|c|c|c|c|c|c|c|}
\hline \multirow[b]{2}{*}{$\mathbf{f}_{w}$} & \multicolumn{3}{|c|}{ KIz 11} & \multicolumn{3}{|c|}{ KIz 1} & \multicolumn{3}{|c|}{ KIz 3} & \multicolumn{3}{|c|}{ KIz 5} \\
\hline & $\lambda_{\mathrm{ab}}$ & $\lambda_{\mathrm{em}}$ & d & $\lambda_{\mathrm{ab}}$ & $\lambda_{\mathrm{em}}$ & d & $\lambda_{\mathrm{ab}}$ & $\lambda_{\mathrm{em}}$ & d & $\lambda_{\mathrm{ab}}$ & $\lambda_{\mathrm{em}}$ & d \\
\hline $\mathbf{0}$ & 369 & 456 & n.a. & 375 & 484 & n.a. & 380 & 492 & n.a. & 399 & 502 & n.a. \\
\hline 10 & 370 & 462 & n.a. & 376 & 498 & n.a. & 382 & 509 & n.a. & 401 & 547 & n.a. \\
\hline 20 & 370 & 475 & n.a. & 375 & 504 & n.a. & 380 & 517 & n.a. & 400 & 545 & n.a. \\
\hline 30 & 371 & 476 & n.a. & 377 & 511 & n.a. & 378 & 524 & n.a. & 398 & 547 & n.a. \\
\hline 40 & 370 & 480 & n.a. & 378 & 515 & n.a. & 382 & 526 & n.a. & 400 & 550 & n.a. \\
\hline 50 & 371 & 484 & n.a. & 378 & 516 & n.a. & 379 & 536 & n.a. & 402 & 556 & 303.6 \\
\hline 60 & 371 & 486 & n.a. & 375 & 515 & 416.1 & 381 & 535 & 272.8 & 404 & 564 & 355.9 \\
\hline 70 & 371 & 487 & n.a. & 374 & 529 & 1073.3 & 385 & 538 & 1047.4 & 405 & 554 & 487.9 \\
\hline 80 & 371 & 488 & 932.98 & 376 & 523 & 814.5 & 383 & 542 & 956.2 & 405 & 556 & 756.1 \\
\hline 90 & 371 & 491 & 935.7 & 374 & 525 & 535.9 & 384 & 537 & 549.3 & 406 & 548 & 376.7 \\
\hline
\end{tabular}

aHexane fractions in THF/Hexane mixture. ${ }^{\mathrm{b}}$ The longest absorption wavelength (nm) . ${ }^{\mathrm{c}}$ Maximal

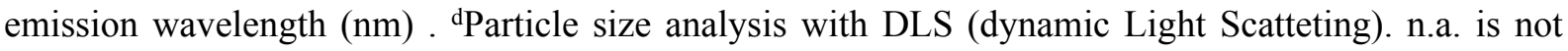
available. 
(a)

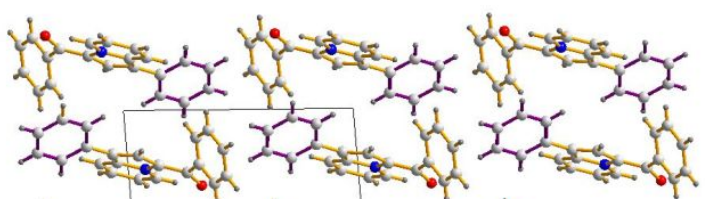
मे में

(c)

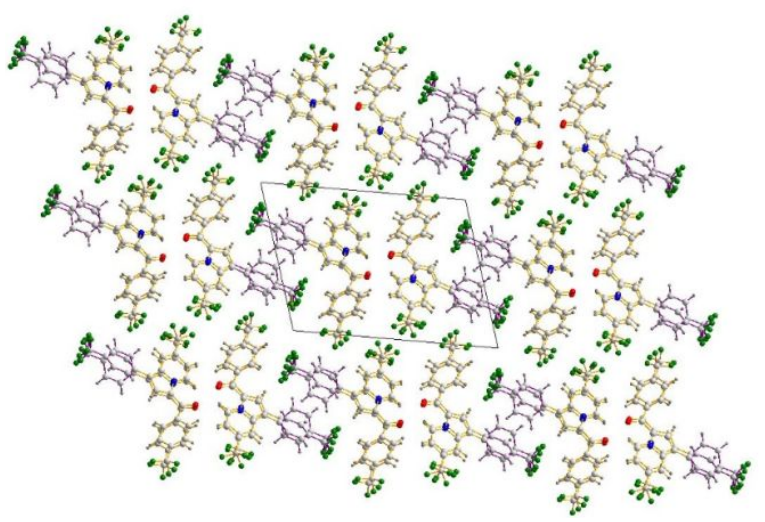

(b)

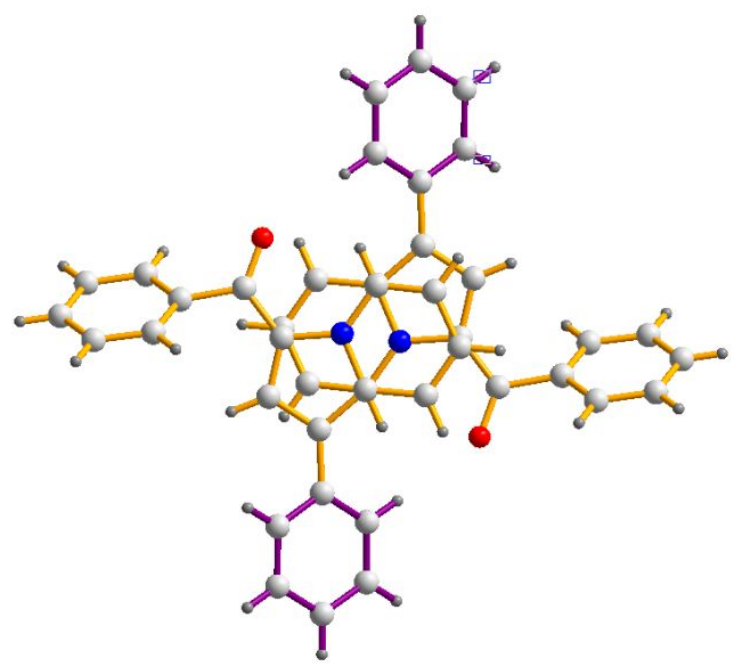

(d)

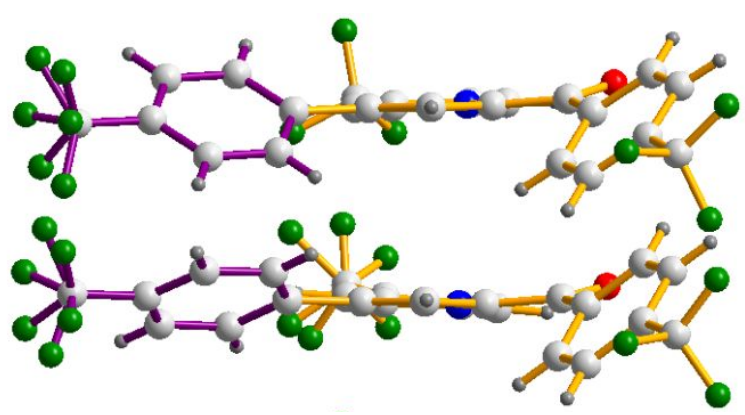

Figure S2. Single crystal structure of $\operatorname{KIz} 63(a, b)$ and of $\operatorname{KIz} 1(c, d)$. 
(a)

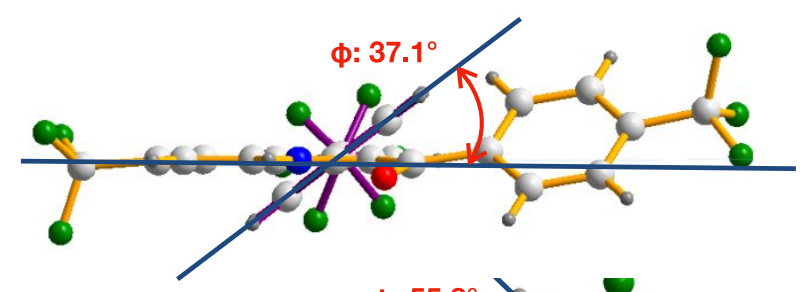

(b)
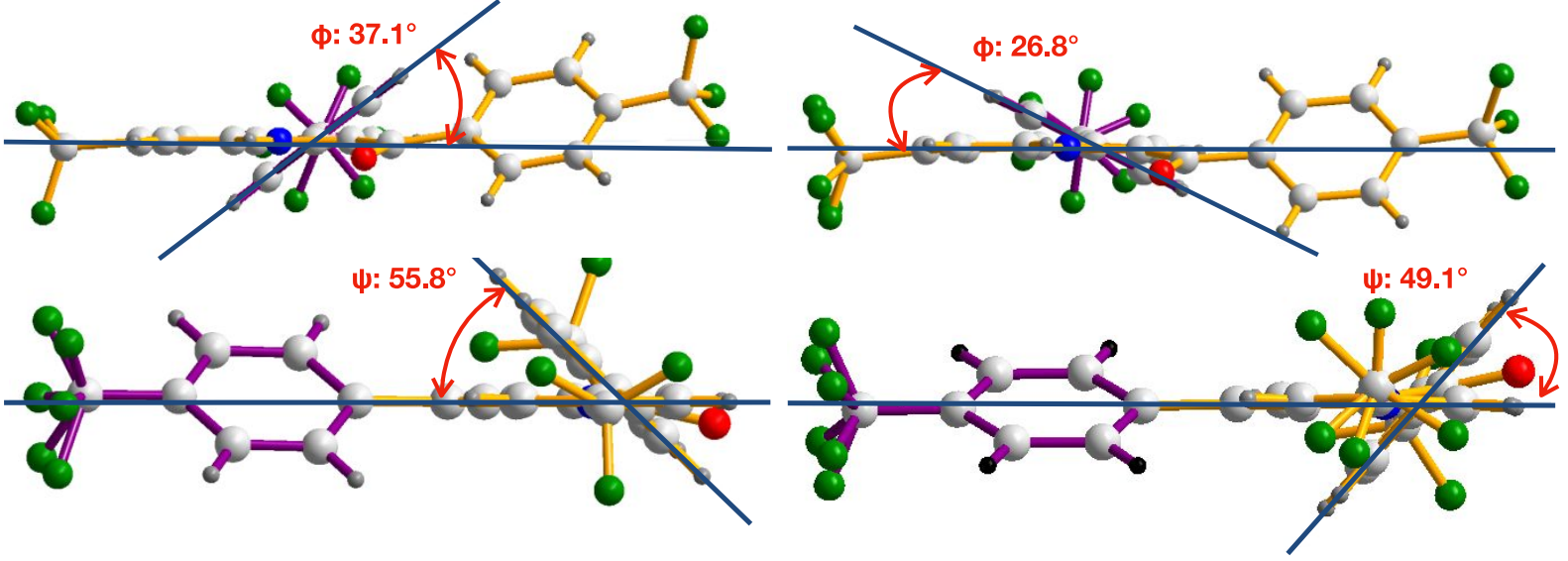

Figure S3. Single crystal structure analysis of KIz 1. 
(a)

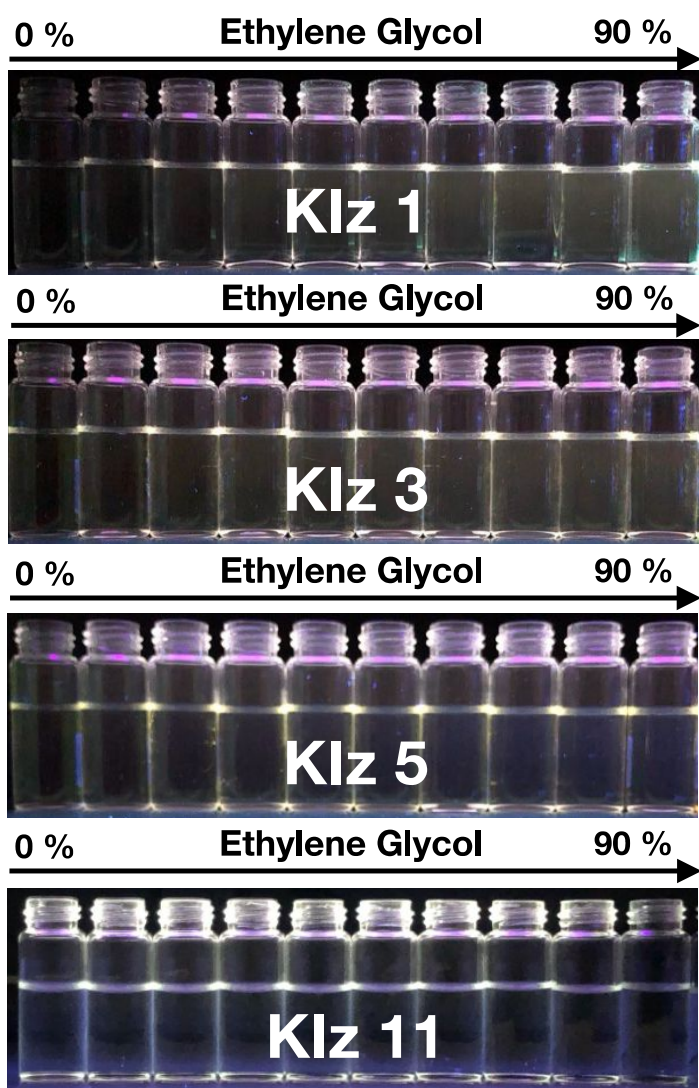

(b)
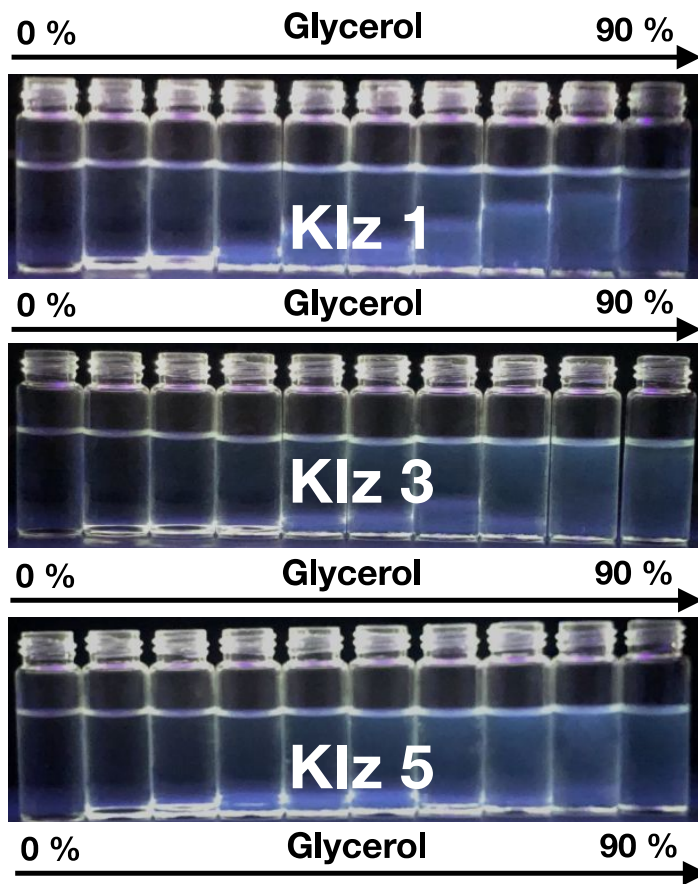

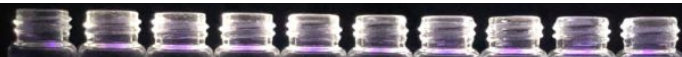

$\mathrm{Klz} 11$

Figure S4. Solution of Kaleidolizine in solvent with different viscosity. Photos of KIz 1, KIz 3, KIz 5 and $\mathrm{KIz} 11$ solution $(20 \mu \mathrm{M})$ in $\mathrm{THF} /$ Ethylene glycol mixture (a) or in $\mathrm{MeOH} / \mathrm{glycerol}$ mixture (b) containing different amount of ethylene glycol or glycerol (0-90\%), respectively. 

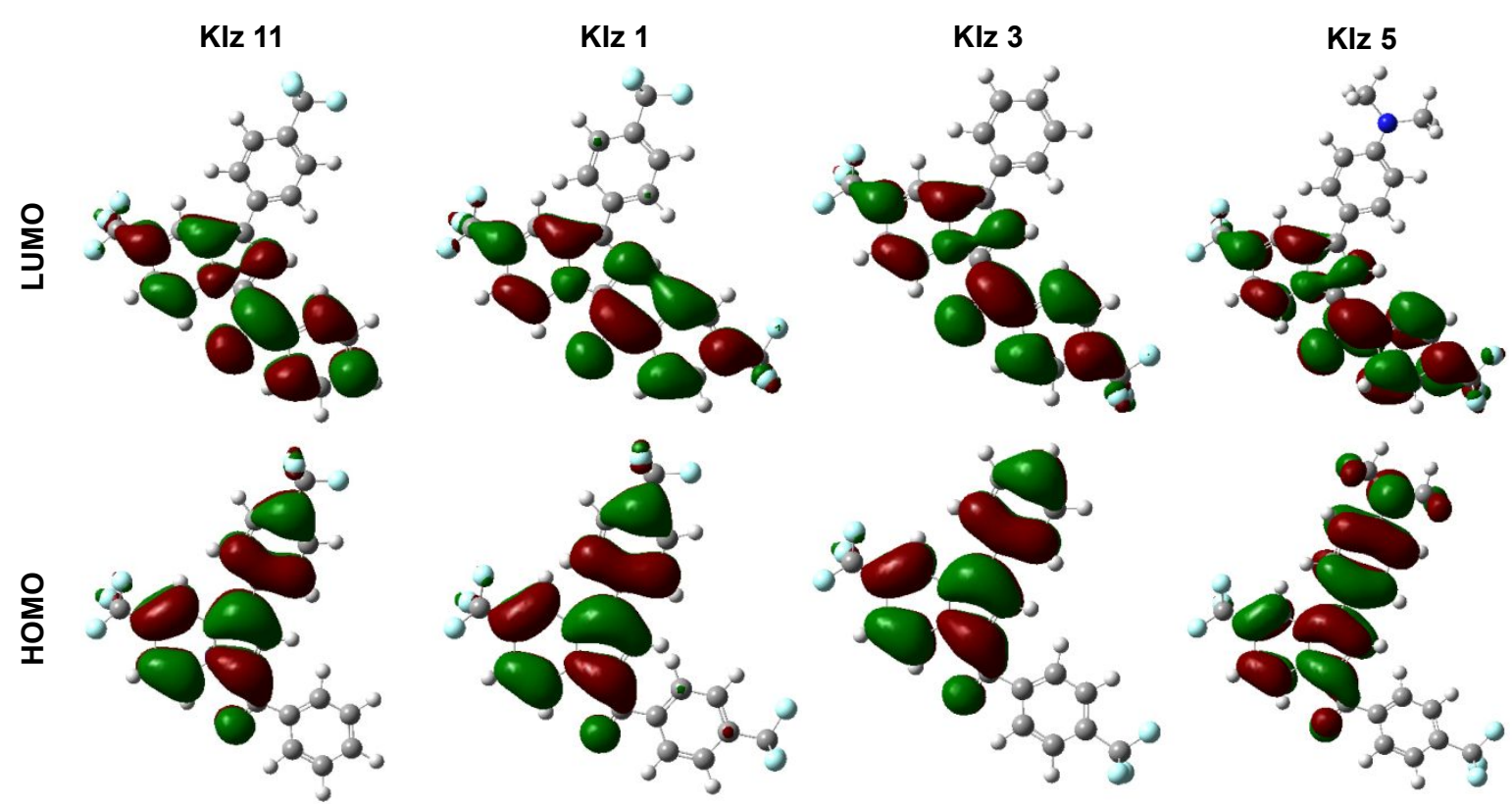

Figure S5. Electron density distributions of HOMO and LUMO of each KIz compounds were calculated by DFT calculation with Gaussian 09 at the B3LYP/6-31G(d) level with the conformations defined with geometry optimization. 
$6 \mathrm{~h}$

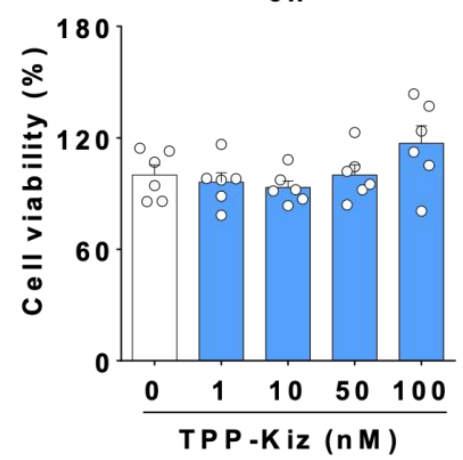

$12 \mathrm{~h}$

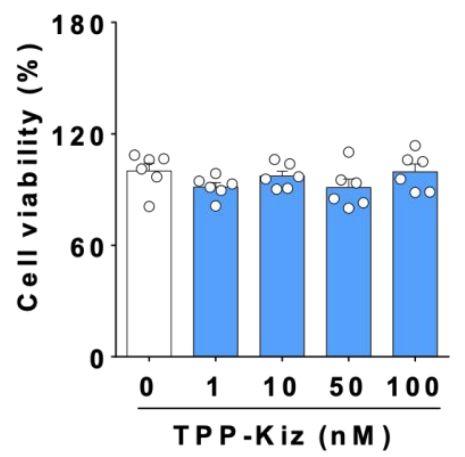

$24 h$

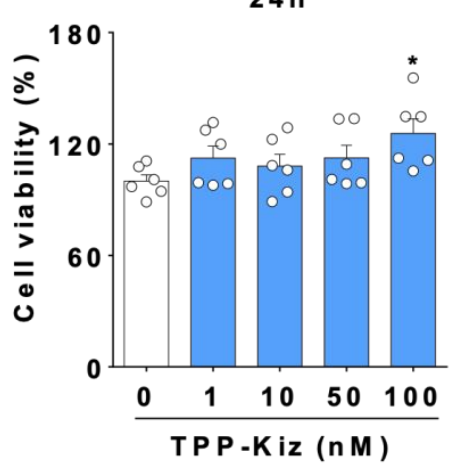

Figure S6. Cytotoxicity test. Chang liver cells were incubated with TPP-KIz, concentration range from $1 \mathrm{nM}$ to $100 \mathrm{nM}$, for 6,12 , and $24 \mathrm{~h}$. Viability of the cells was normalized by DMSO control. 

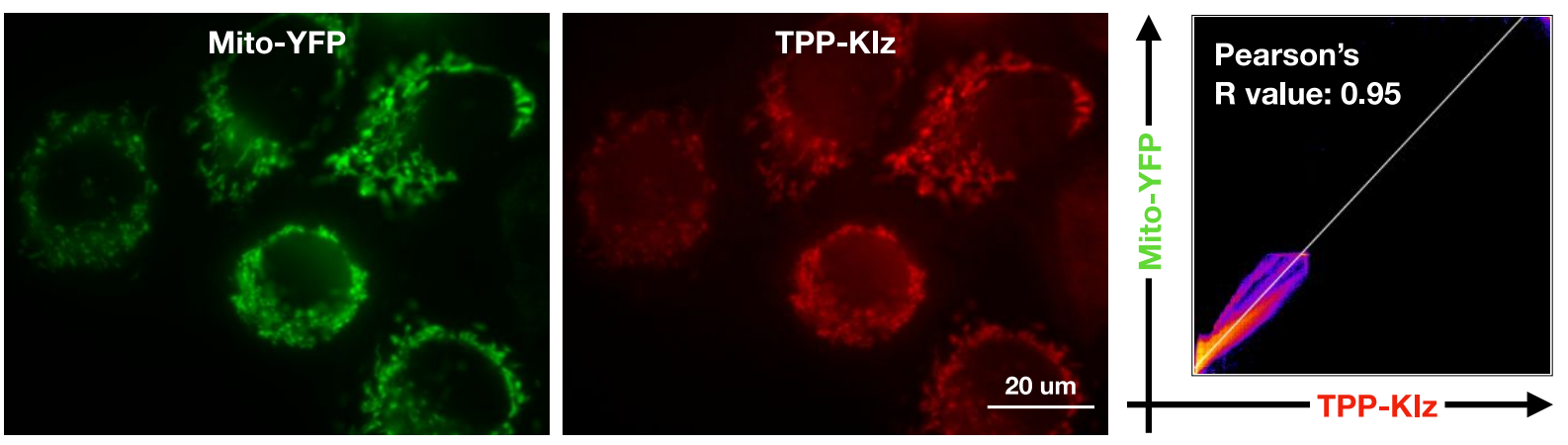

Figure S7. Colocalization experiment. Chang liver cells expressing mitochondrial Yellow Fluorescent protein (Mito-YFP) were treated with $1 \mathrm{nM}$ of TPP-KIz and imaged with LEICA DMi8 microscope. Pearson coefficient (0.95) between the signal from Mito-YFP and TPP-KIz revealed excellent specificity of the TPP-KIz for fluorescent mitochondria staining without washing (Scale bar $=20 \mu \mathrm{m}$ ). 


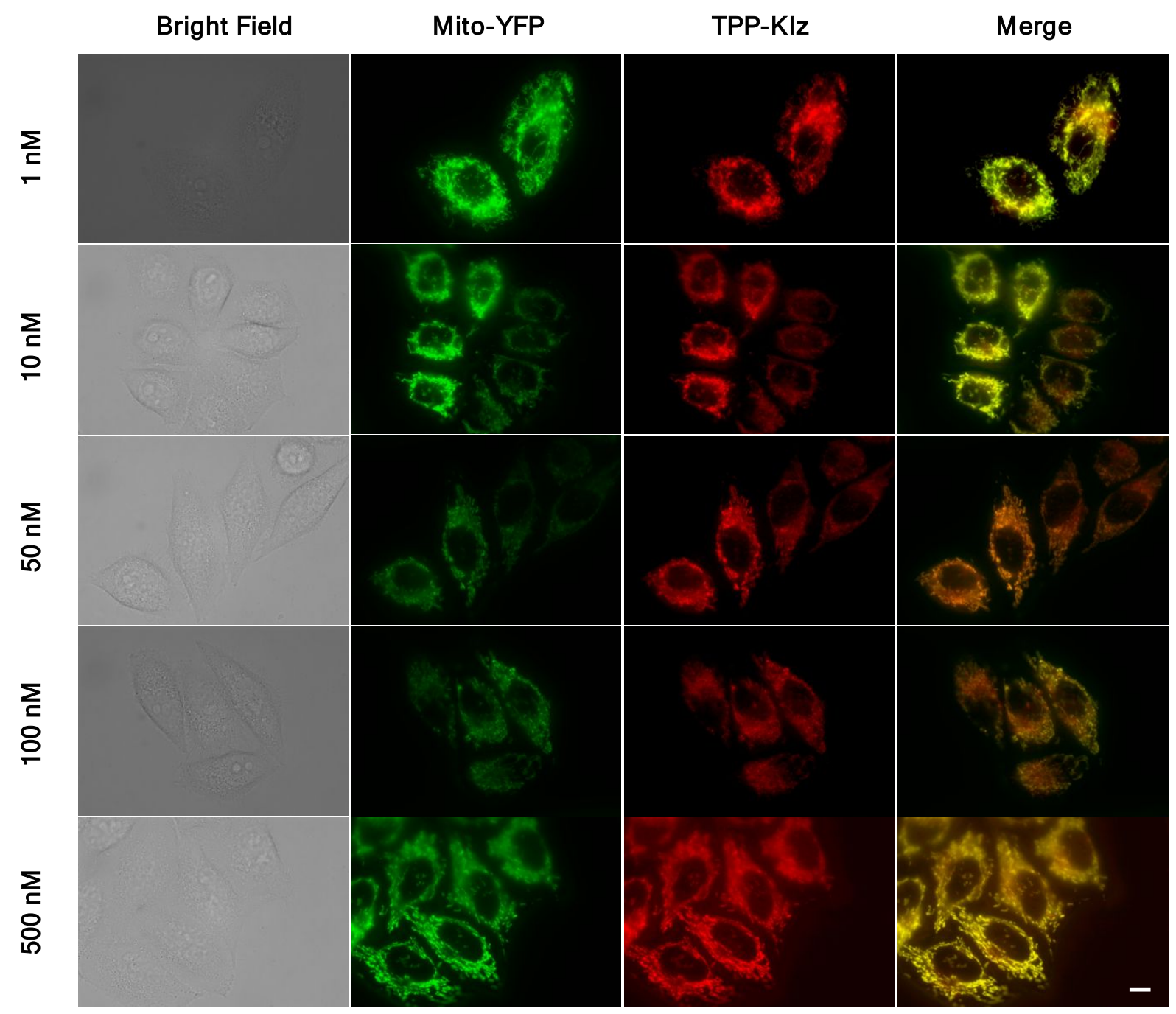

Figure S8. Fluorogenic imaging of mitochondria with TPP-KIz in live cell condition without washing. Chang liver cells expressing mitochondrial Yellow Fluorescent protein (Mito-YFP) were incubated with TPP-KIz (from $500 \mathrm{nM}$ to $1 \mathrm{nM}$ ) and imaged with DMi8 fluorescence microscopy without washing. Merged image showed excellent colocalization between the signal from Mito-YFP and from TPP-KIz. $($ Scale bar $=10 \mu \mathrm{m})$ 


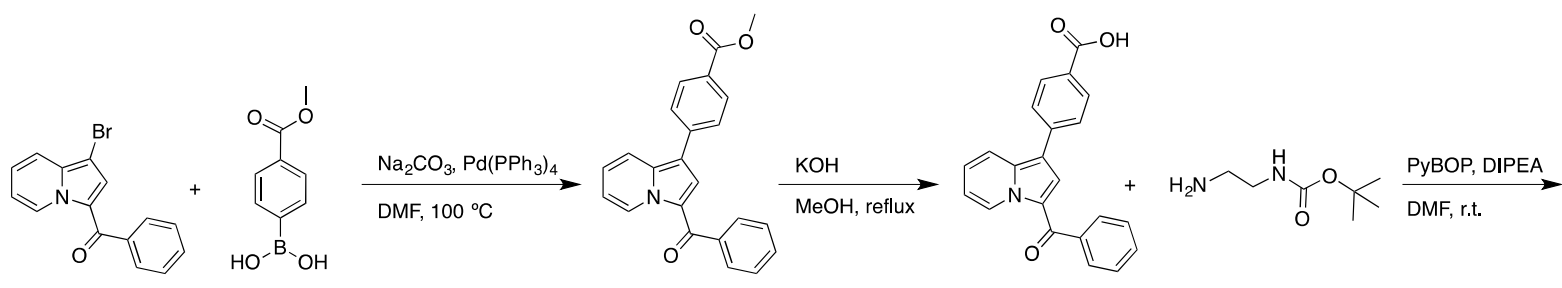

IM-B

Compound 1

Compound 2

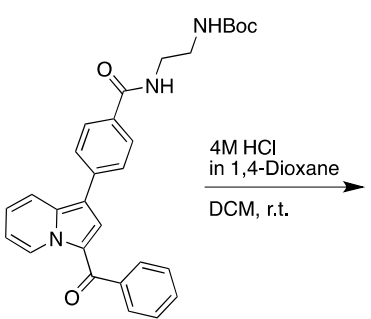

Compound 3

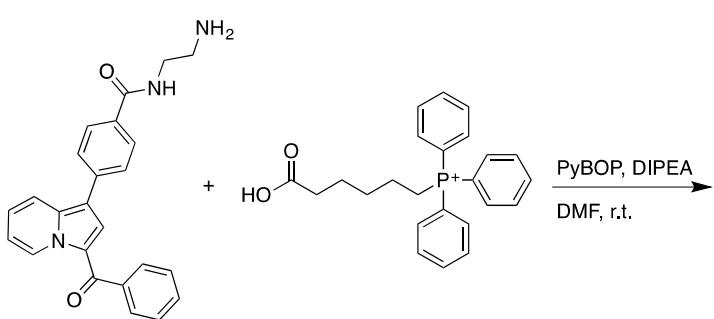

Compound 4

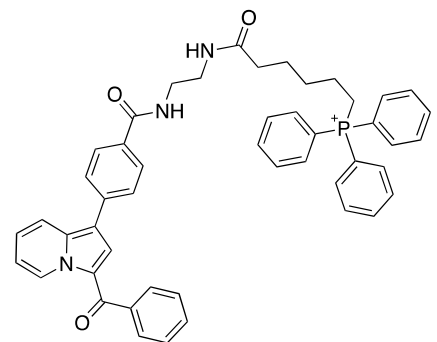

TPP-KIz

Scheme S1. Synthesis of TPP-KIz. 
Table S2. Crystal Structure analysis.

\begin{tabular}{|c|c|c|}
\hline Compound & Klz 63 & Klz 1 \\
\hline crystal system & Triclinic & Triclinic \\
\hline space group & $\mathrm{P}-1$ & 9.7026 \\
\hline$a(\AA)$ & 7.9261 & 13.9432 \\
\hline$b(\AA)$ & 9.6249 & 17.8604 \\
\hline$c(\AA)$ & 11.2209 & 70.921 \\
\hline$\alpha($ deg.) & 82.808 & 81.713 \\
\hline $\mathrm{b}($ deg. $)$ & 80.659 & 69.302 \\
\hline$\gamma($ deg. $)$ & 68.917 & 2135.02 \\
\hline$V(\AA 3)$ & 786.05 & 2 \\
\hline $\mathrm{Z}$ & 2 & 1002.69 \\
\hline $\mathrm{M} . \mathrm{W}$ & 297.34 & \\
\hline
\end{tabular}

KIz 1 Crystal: 16555 reflections collected in the $\theta$ range $3.1^{\circ}-25.0^{\circ}$ using $\omega$ scans on a Rigaku R-axis Rapid S diffractometer, 7404 were unique reflections $\left(R_{\text {int }}=0.0454\right)$. The structure was solved and refined against $\mathrm{F}^{2}$ using SHELXL-2018/3, ${ }^{[1]} 687$ variables, $w R_{2}=0.1843, R_{1}=0.0588\left(\mathrm{Fo}^{2}>2 \sigma\left(\mathrm{Fo}^{2}\right)\right)$, $\mathrm{GOF}=1.068$, and $\mathrm{max} / \mathrm{min}$ residual electron density $0.870 /-0.481 \mathrm{e}^{-3} . \mathrm{CCDC}-2014525$.

KIz 63 Crystal: 7777 reflections collected in the $\theta$ range $3.0^{\circ}-27.5^{\circ}$ using $\omega$ scans on a Rigaku R-axis Rapid S diffractometer, 3568 were unique reflections $\left(R_{\text {int }}=0.0182\right)$. The structure was solved and refined against $\mathrm{F}^{2}$ using SHELXL-2018/3, ${ }^{[1]} 209$ variables, $w R_{2}=0.1170, R_{1}=0.0371\left(\mathrm{Fo}^{2}>2 \sigma\left(\mathrm{Fo}^{2}\right)\right)$, $\mathrm{GOF}=1.110$, and $\mathrm{max} / \mathrm{min}$ residual electron density $0.164 /-0.148 \mathrm{e}^{-3} . \mathrm{CCDC}-2015429$.

[CCDC 2014525 contains the supplementary crystallographic data for this study. These data can be obtained free of charge from the Cambridge Crystallographic Data Centre via www.ccdc.cam.ac.uk/data_request/cif.] 
2. Copies of ${ }^{1} \mathrm{H}$ and ${ }^{13} \mathrm{C}$ NMR Spectra of a New Compounds

Compound IA-E
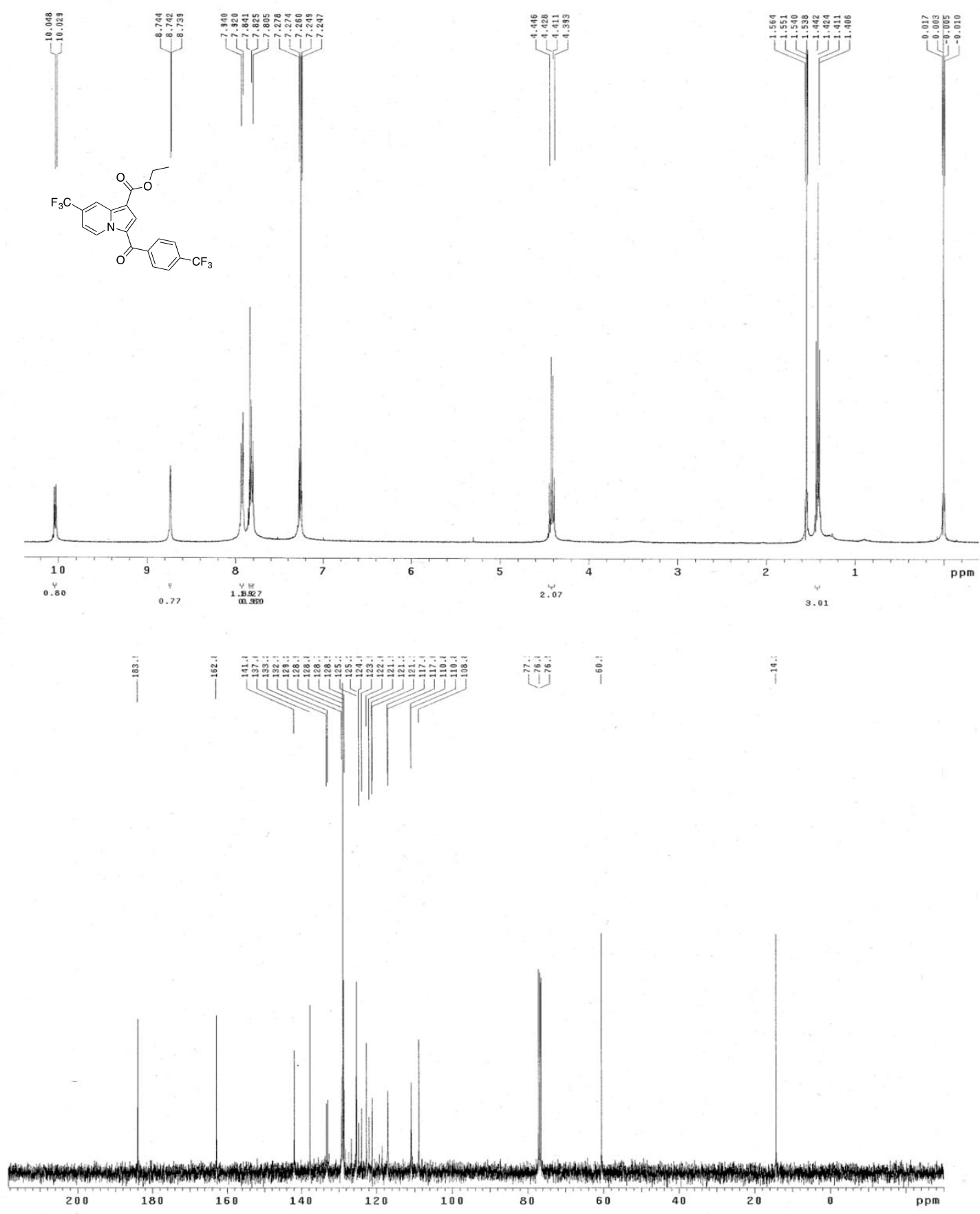
Compound IA-B
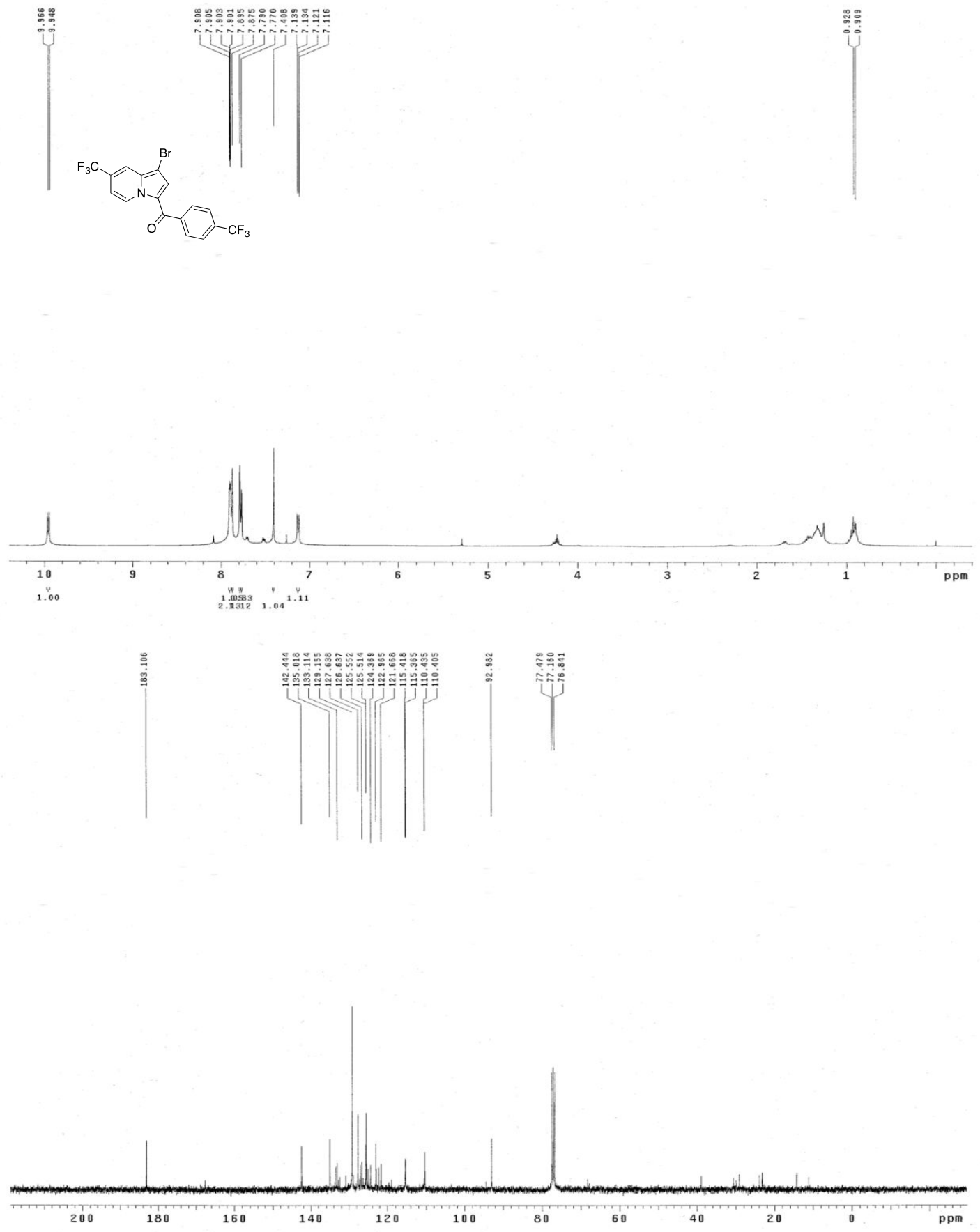
KIz 1
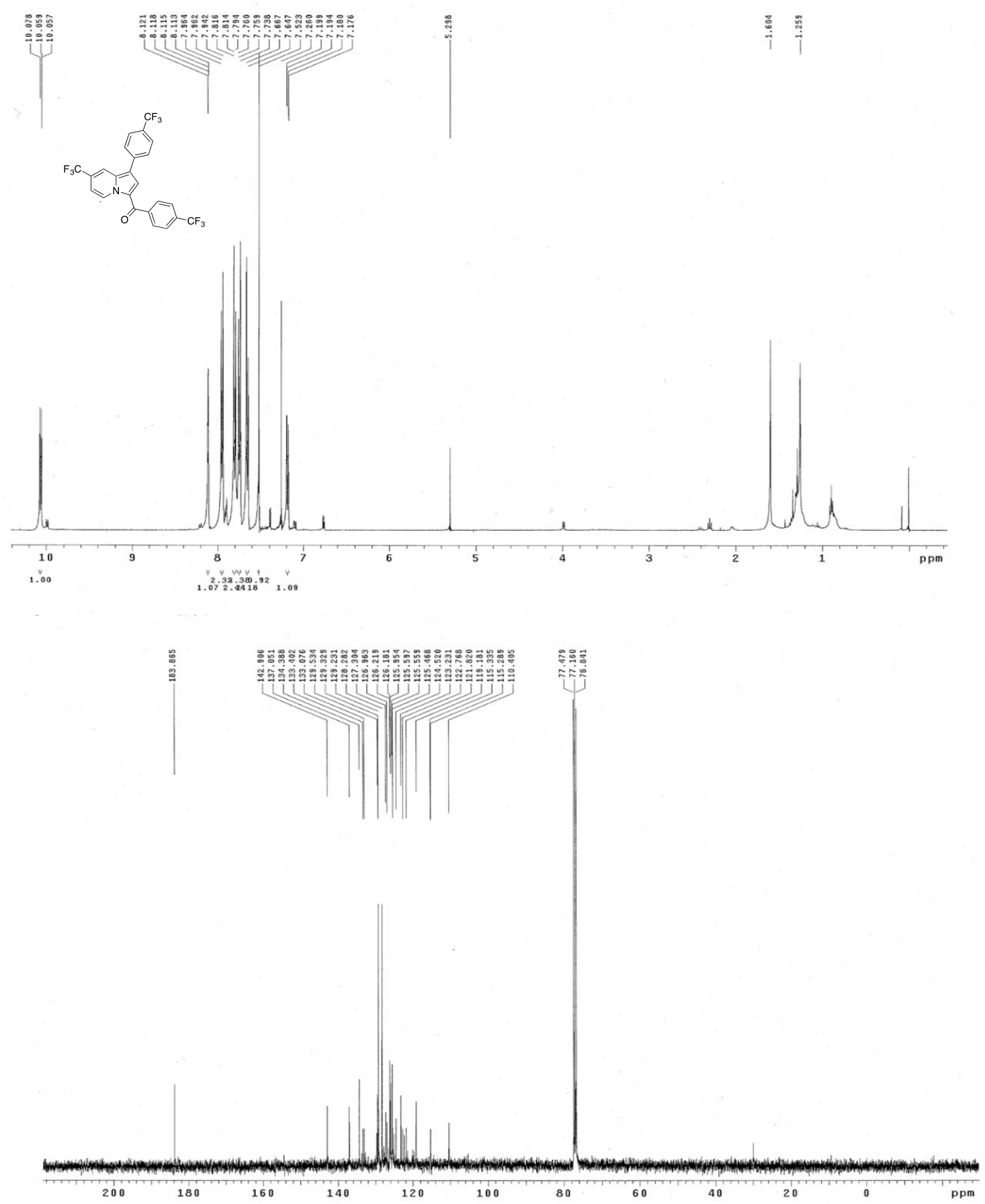


\section{KIz 3}
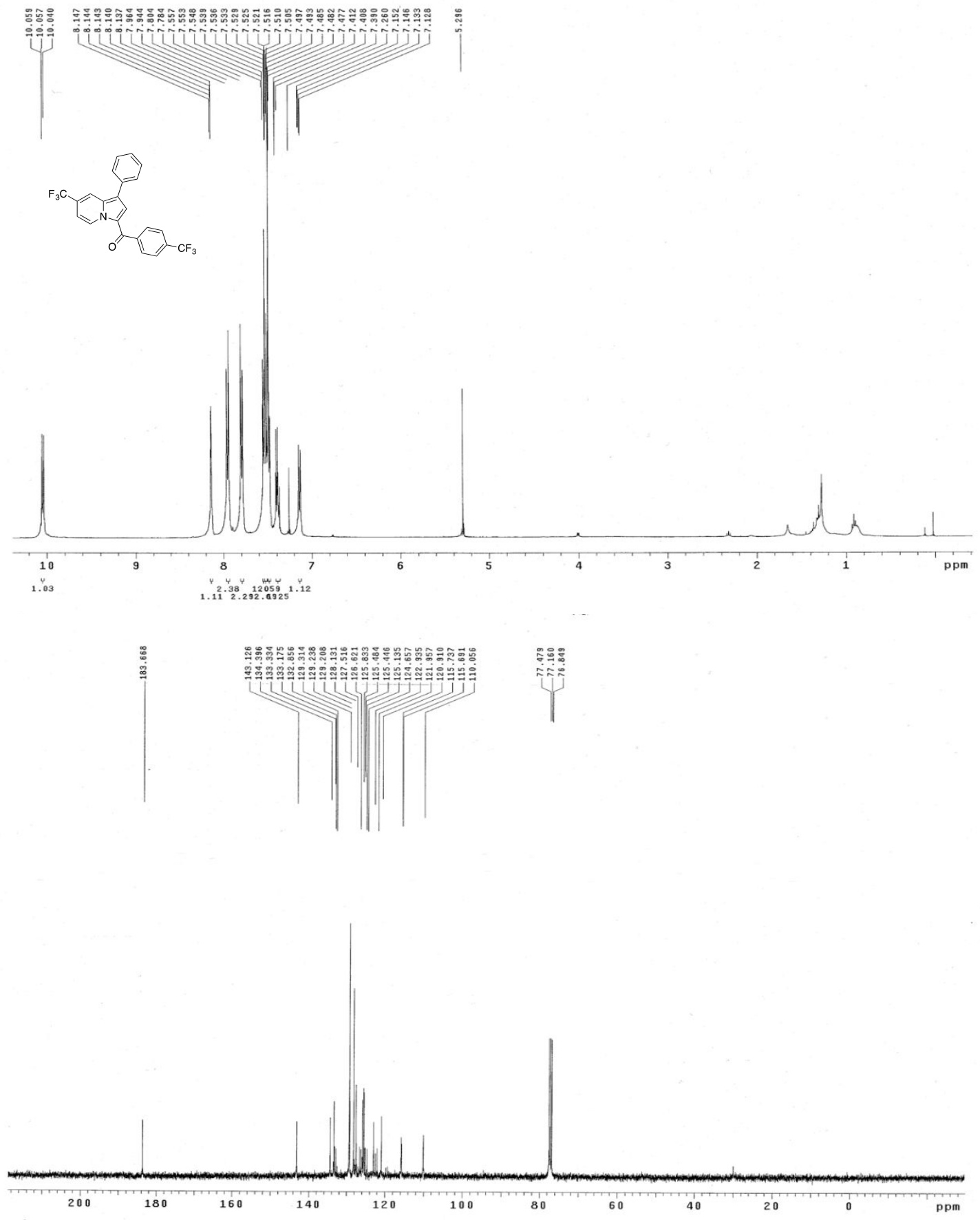
KIz 5
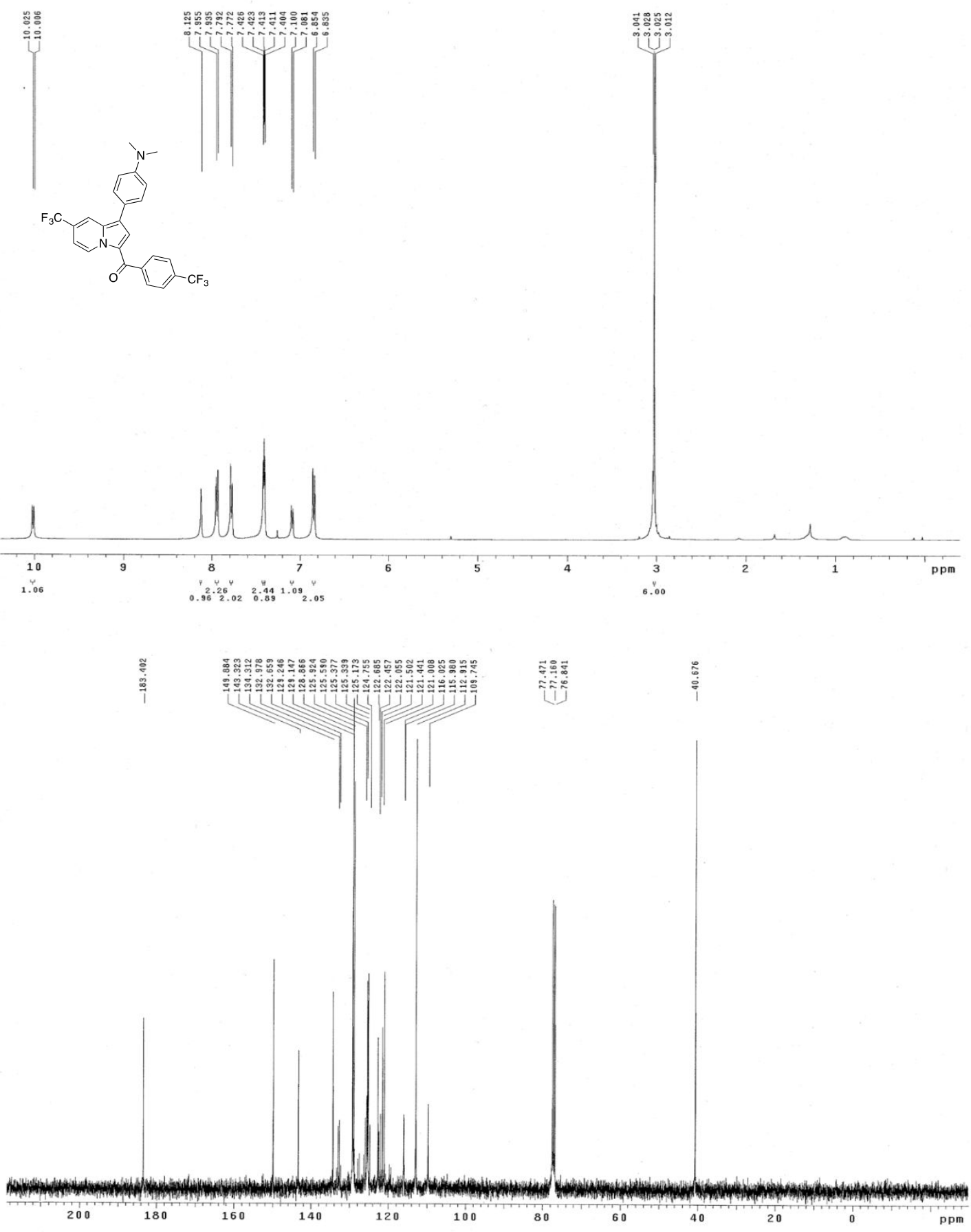
Compound IC-E
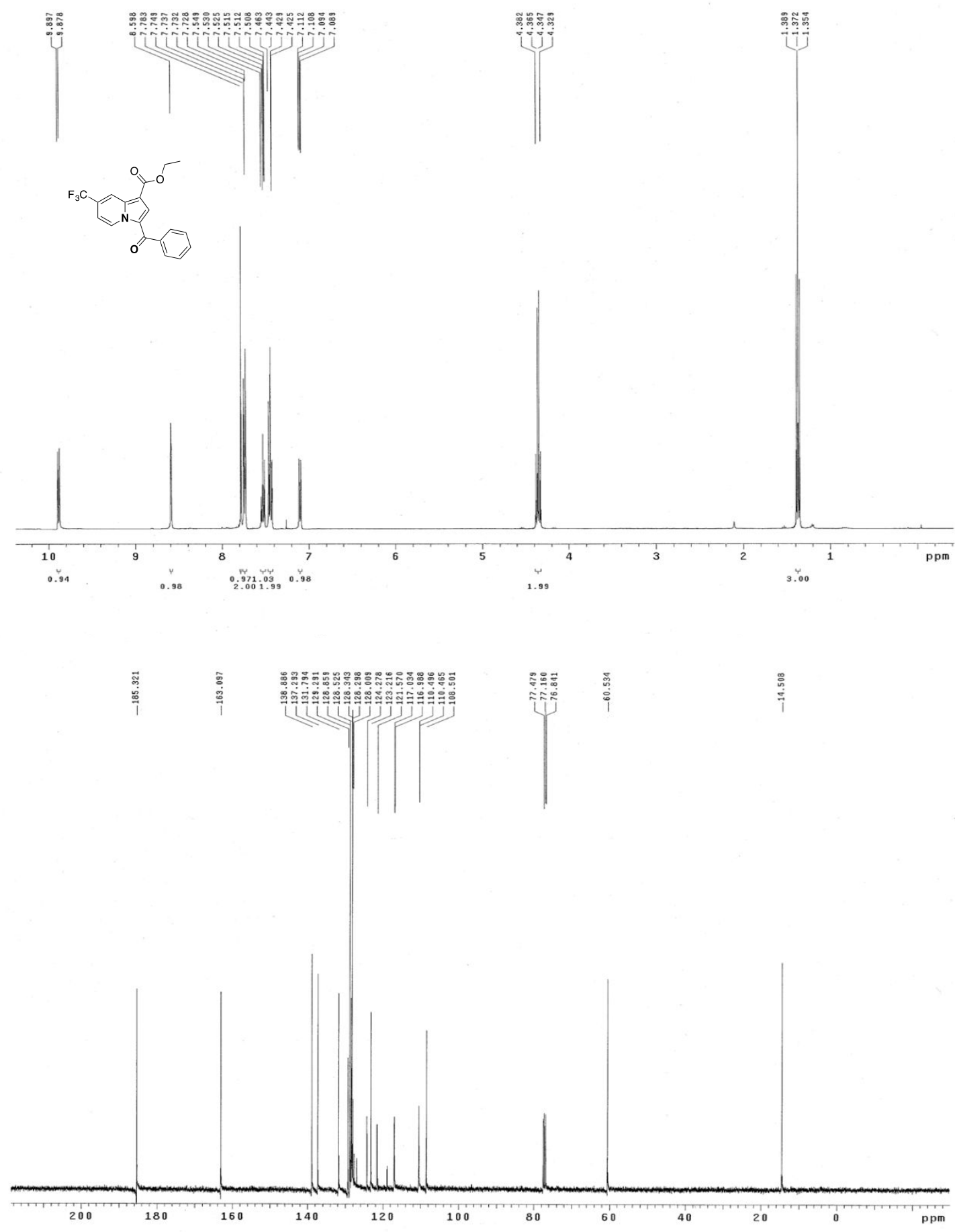
Compound IC-B
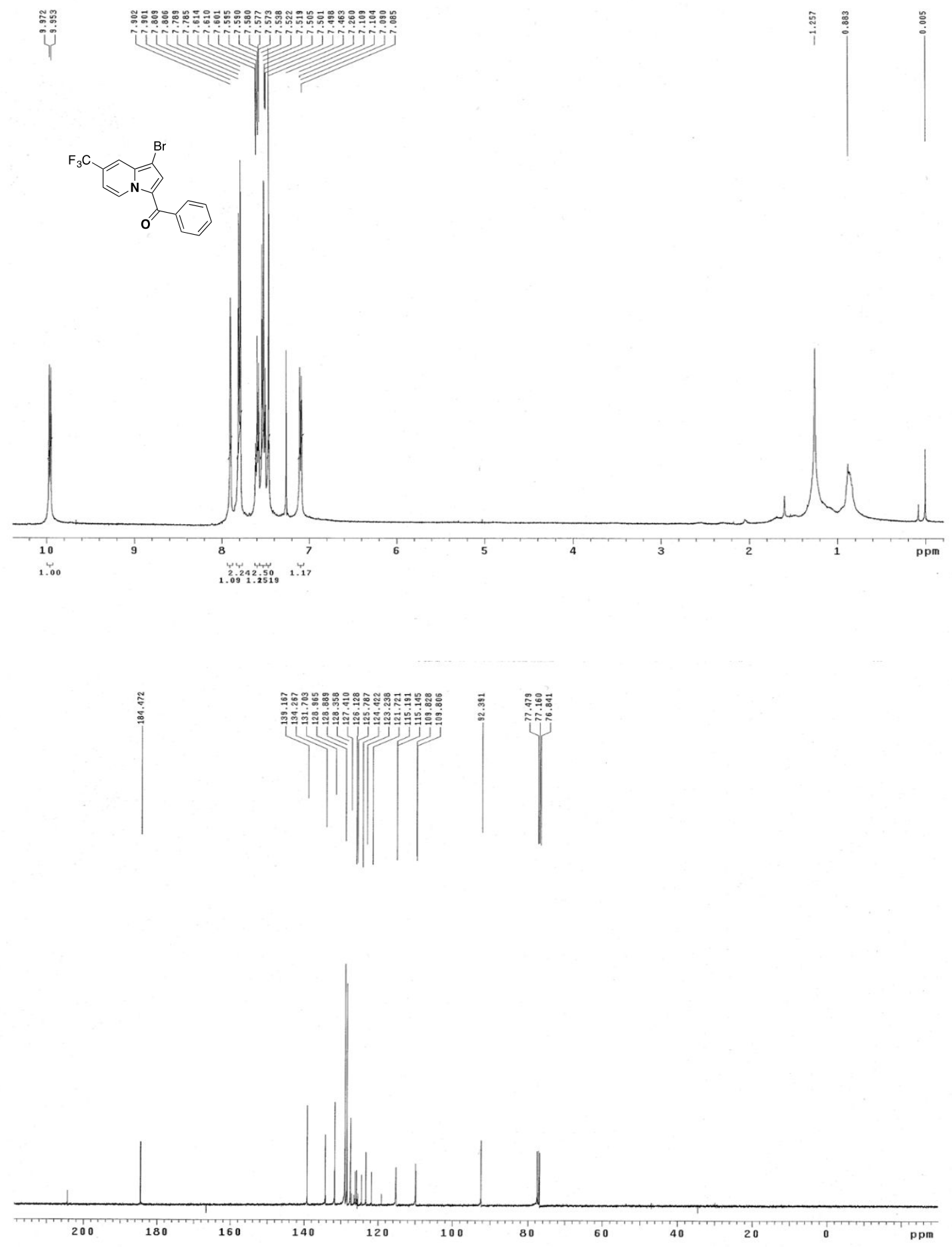
KIz 11
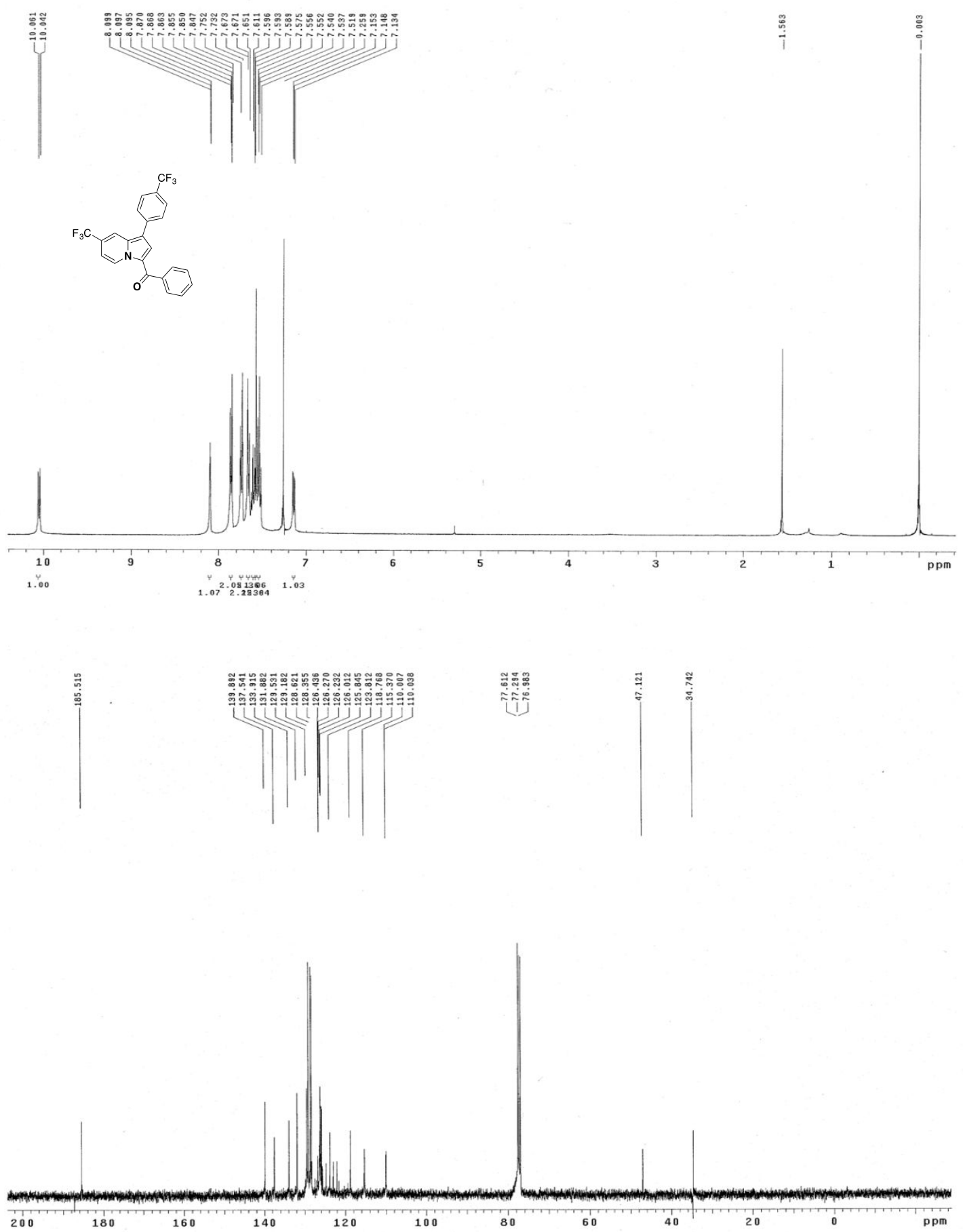
Compound IM-E
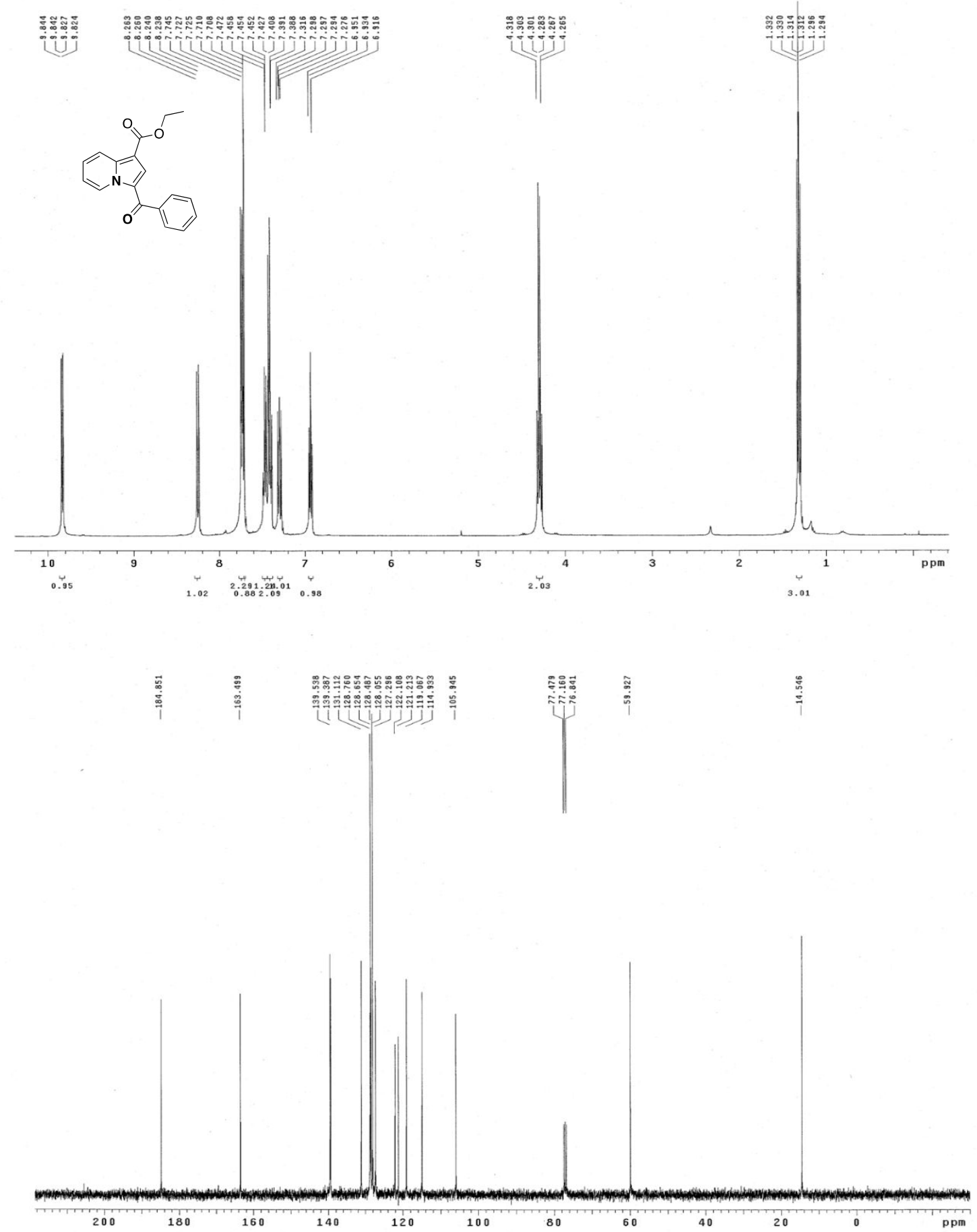
KIz 63
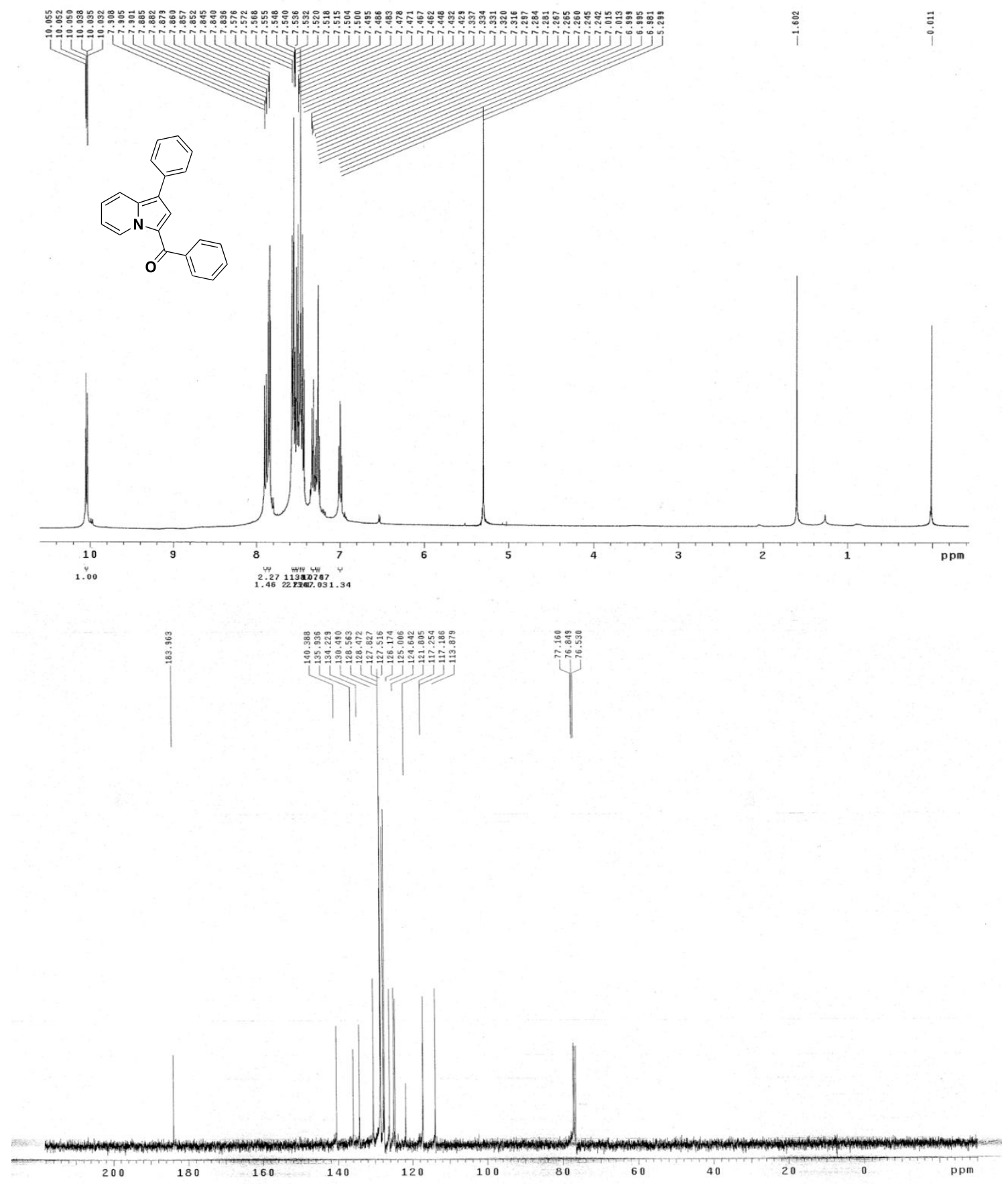


\section{Compound 1}

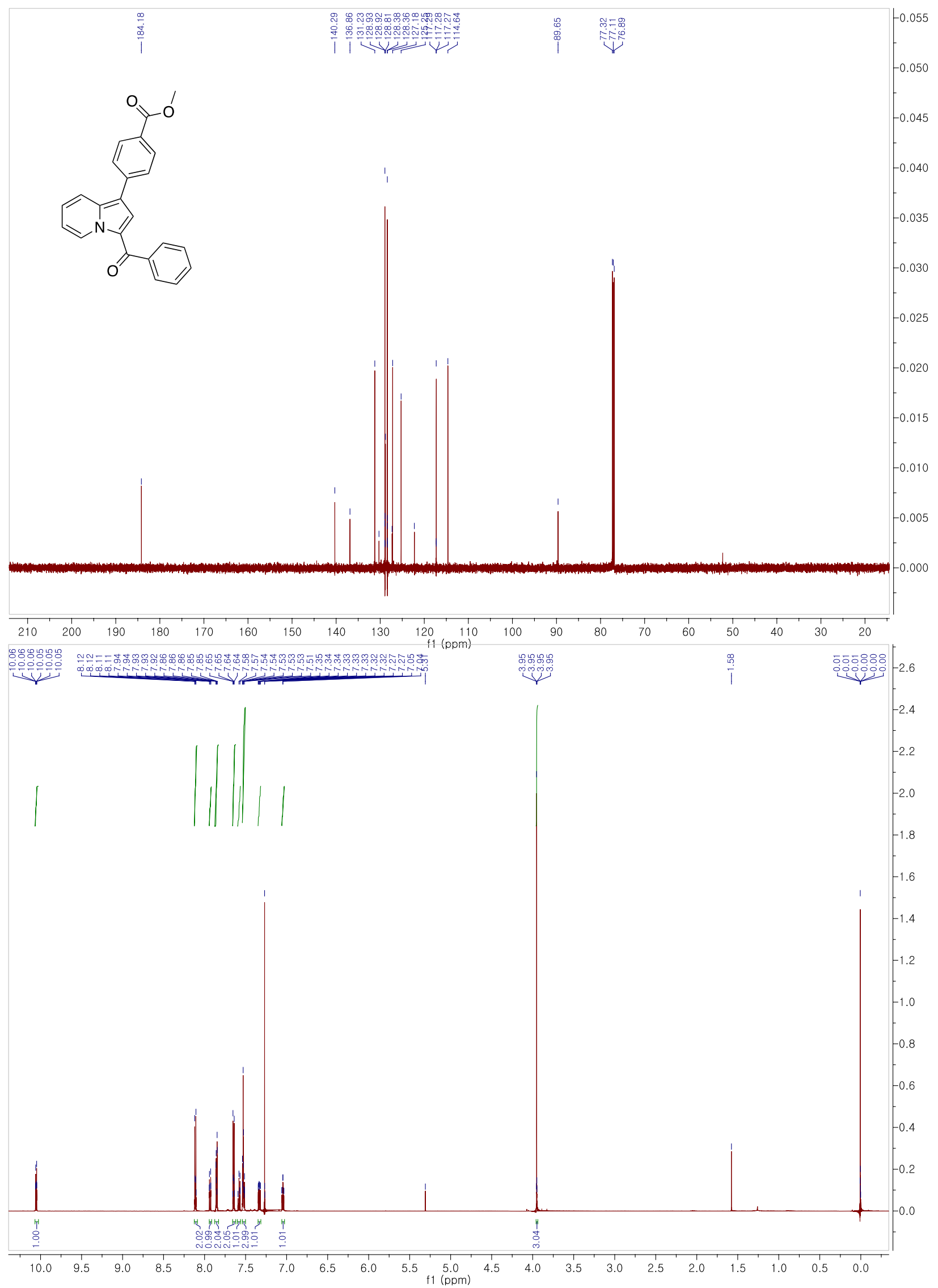




\section{Compound 2}

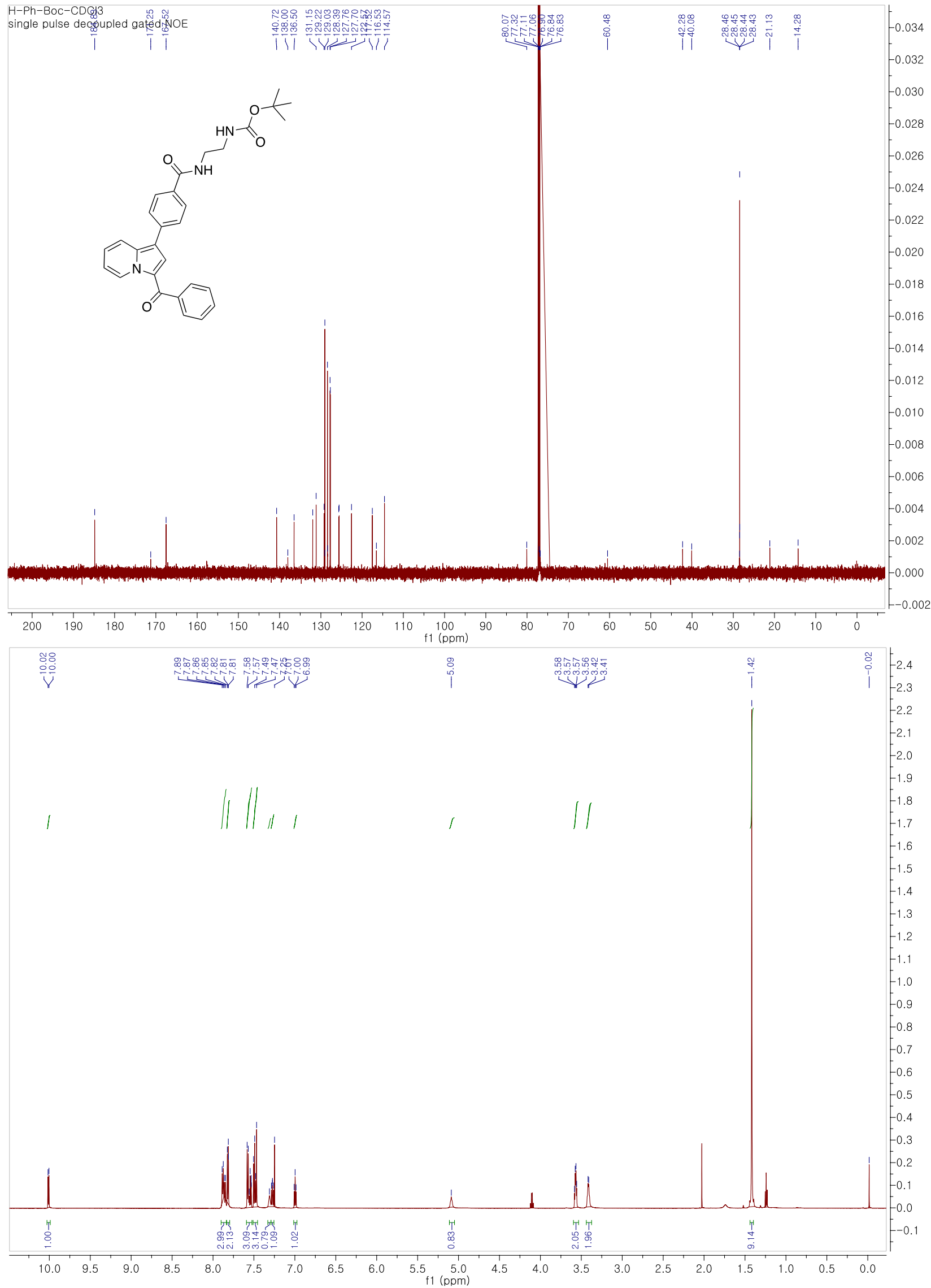


TPP-KIz
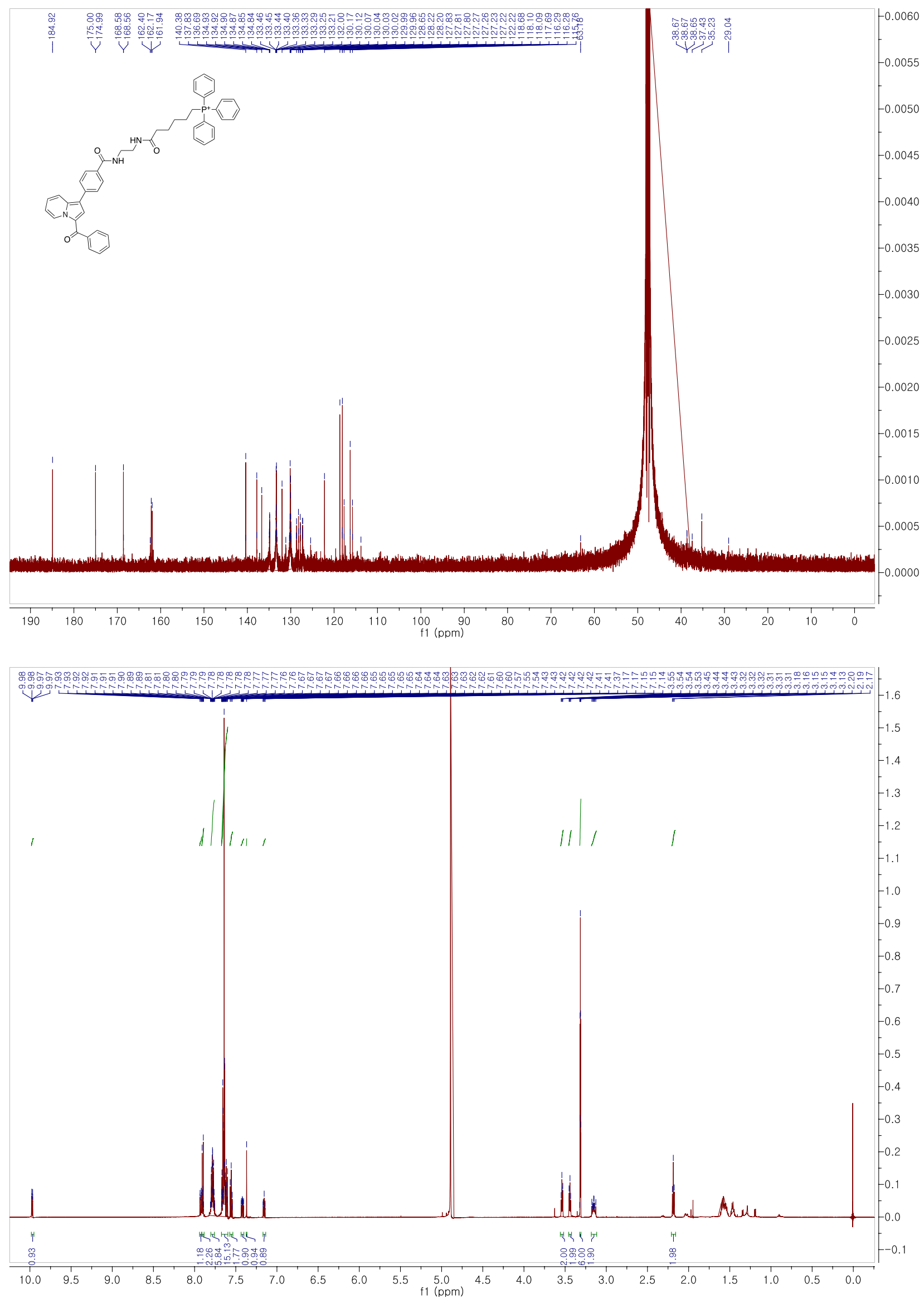
3. Reference

[1] G. M. Shleldrick, Acta Cryst. 2015, C71, 3-8. 